\title{
A influência teórica do militante espanhol Abraham Guillén em grupos de luta armada na América Latina
}

Carla Luciana Silva ${ }^{1}$

\begin{abstract}
Resumo: O objetivo deste texto é apresentar a influência de um teórico revolucionário pouco conhecido no debate sobre a luta armada brasileira. A maioria dos textos sobre o tema debatem a influência de Che Guevara e Regis Debray. Argumentamos aqui que a concepção de guerrilha no Brasil se aproximou da teoria do revolucionário Abraham Guillén. No final dos anos 1960, ele participou de várias estratégias de luta, na Bolívia, Argentina e Uruguai. Sua tese, de que a luta deveria se dar também no meio urbano, destoava da teoria do foquismo. Descobrimos que um grupo de militantes brasileiros exilados no Chile, em um momento de refluxo da luta no Brasil, estudou a obra de Guillén e elaborou um documento base para pautar a volta ao país, o Documento dos Doze Pontos. Parte dos registros são localizados no acompanhamento que a repressão brasileira, por meio do Centro de Informação do Exército - CIEX, fez dos passos de Guillén e do fluxo de revolucionários nos países do Conesul. As referências teóricas usadas pelos movimentos revolucionários ultrapassavam as fronteiras nacionais e iam muito além dos conhecidos Che Guevara e Regis Debray.
\end{abstract}

Palavras-chave: Abraham Guillén; Foquismo; Luta Armada.

\section{The theoretical influence of the Spanish militant Abrahan Guillén on armed struggle groups in Latin America}

\begin{abstract}
The purpose of this text is to present the influence of a revolutionary theorist, who is little known in the debate about the Brazilian armed struggle. Most of the texts on this subject debate the influence of Che Guevara and Régis Debray. However, we argue here that the conception of guerrillas in Brazil came closer to the theory of the revolutionary Abrahan Guillén. In the late 1960s, he took part in various fighting strategies in Bolivia, Argentina, and Uruguay. His thesis, that the fight should also take place in the urban environment, differs from the Foco Theory. We discovered that a group of Brazilian militants exiled in Chile, at a time when the struggle in Brazil was receding, studied Guillén's work and prepared a base document to guide their return to the country, the Document of the Twelve Points. Part of these records are located in the monitoring that the Brazilian repression, through the Army Information Center (known as CIEX), made of the steps of Guillén and the flow of revolutionaries in the countries
\end{abstract}

\footnotetext{
${ }^{1}$ Doutora em História. UNIOESTE. Esta pesquisa foi realizada com apoio da Fundação Araucária, no projeto de pesquisa Resistência à Ditadura: Problematizando A VPR no Sul do Brasil e Conesul, faz parte dos resultados do Pós Doutorado realizado na UFF (2019-2020). carlalusi@gmail.com, https://orcid.org/0000-0001-6838-0394
} 
of the Southern Cone Region. The theoretical references used by revolutionary movements went beyond national borders and went well beyond the well-known Che Guevara and Régis Debray.

Keywords: Abrahan Guillén, Foco Theory, Armed Struggle.

Artigo recebido em: 28/09/2020

Artigo aprovado para publicação em: 07/04/2021

\section{Introdução}

Este artigo tem como pano de fundo a luta armada latino-americana no contexto das ditaduras de Segurança Nacional. Embora fossem nacionais, as organizações de luta de resistência às Ditaduras do Conesul se guiavam por um ideário internacionalista, o que estimulava ações de solidariedade na luta. Os militantes, homens e mulheres, atuaram, em distintos momentos, em mais de um país, sobretudo em momentos de asilo ou exílio, sob vida legal ou totalmente clandestina. A ida para países vizinhos poderia se dar por motivos de segurança, mas também de organização para posterior volta ao país de origem. Por isso as fronteiras eram espaço de vigilância, assim como de solidariedade. Para além dos limites restritivos, os contatos entre os países do Conesul foram permanentes durante as ditaduras, como corredores de acolhimento e passagem, sendo, por conseguinte, altamente vigiados. Trataremos de militantes que seguiam atuando fora de suas terras de origem, alimentando a perspectiva revolucionária, tão presente nos anos 1970.

O caso que exploramos neste artigo é a influência das teorias do espanhol Abraham Guillén nas teorias revolucionárias brasileiras, até o momento pouco conhecido na historiografia brasileira. As condições de produção e divulgação estavam situadas fora do Brasil, e o artigo busca apontar como a obra chegou ao país, ainda que de forma truncada e mediada pelas forças repressivas. $\mathrm{O}$ artigo tratará de dois aspectos da contribuição de Guillén: a originalidade de sua contribuição diante dos referenciais teóricos disponíveis para os grupos em luta. Argumentamos que essa contribuição não foi até hoje reconhecida na historiografia brasileira. Em um segundo momento, o uso parcial que é feito do seu texto, o Documento dos Doze Pontos, por meio do acompanhamento de suas ações realizadas pelos aparelhos de repressão brasileiros. 
Militantes realizavam o autêntico debate de sua obra, e a repressão acompanha esse fluxo, tentando atrair militantes de volta ao país para serem exterminados.

\section{Abraham Guillén, sua importância e obra}

Abraham Guillén nasceu em Guadalajara, Espanha, em 1913, e morreu no mesmo país, em 1993. Lutou na Guerra Civil Espanhola, como membro da CNT ${ }^{2}$. Preso em Alicante, conseguiu fugir em 1945 e iniciou seu longo exílio. Voltaria à Espanha apenas após a morte de Franco, em 1975. Seu interesse pelo anarquismo demarcou toda sua trajetória de vida. Formado em economia, atuou como teórico ativo de políticas de autogestão. Fugido da Europa e do fascismo na Espanha, encontraria na América Latina a oportunidade de seguir sua militância política. Seu conhecimento foi utilizado por vários grupos que buscavam alternativas de resistência. Sobretudo, no sentido de traçar alternativas de luta que não fossem a reprodução da "guerra de guerrilha", seja na sua concepção guevarista, seja na leitura de Regis Debray, que obteve grande recepção no Brasil e na Argentina.

Em um de seus livros, ele apresenta seu "autorretrato": "Minha maior sorte foi sobreviver à sangrenta guerra civil e à cruenta repressão que lhe seguiu. Por amor à liberdade, fugi duas vezes de prisões franquistas, com grande risco para minha vida" (GUILLÉN, 1969). No exílio, sua atuação se coloca como a de um intelectual a serviço da causa revolucionária. Falecido em 1993, deixou escritos e havia publicado mais de cinquenta livros ${ }^{3}$, e segue sendo referência para movimentos libertários e auto gestionários.

Guillén saiu da Espanha já com diploma de economista, alcançado com bolsa de estudos durante a Segunda República. Refugiou-se na Argentina, país no qual já

\footnotetext{
${ }^{2}$ Para conhecer sobre sua atuação naquele processo, indicamos sua biografia: MIRAMAR, José Luis Carretero ABRAHAM GUILLÉN: Guerrilla y autogestión. MADRID, Confederación Sindical Solidaridad Obrera, 2020. Segundo nos informou o autor, a obra será publicada traduzida no Brasil em breve. Citamos aqui a versão original. Todas as traduções do espanhol e do inglês neste artigo foram realizadas pela autoria do artigo.

${ }^{3}$ Uma lista de seus livros pode ser encontrada no Instituto de Ciencias Económicas y de la autogestión: http://www.iceautogestion.org/ Biografias. Consultado em 4/4/2021.
} 
estava exilado seu pai. Posteriormente se estabeleceu no Uruguai, onde sua obra está diretamente vinculada aos tupamaros e ao OPR-33 (Organização Popular Revolucionária, de matiz anarco-sindicalista). Ele também analisou as guerrilhas brasileiras, foi lido no $\mathrm{Chile}^{4}$ por militantes brasileiros e através do Uruguai sua obra chegou parcialmente ao Brasil. Sua atuação intelectual se deu, portanto, sob exílio, que começou na França, estendeu-se a Argentina e posteriormente ao Uruguai, com passagem por Cuba. Os dados sobre sua presença em Cuba mostram que já adquirira conhecimentos de formas de lutas de guerra revolucionária e participara de discussões sobre métodos, inclusive com Che Guevara, quem considerava disciplinado em relação a Fidel Castro, mas dogmático. Guillén achava um equívoco a estratégia do foquismo, como trataremos adiante.

Ele produzia suporte teórico, mas também assessoria a planejamentos de táticas. Nesse âmbito, suas ações mais relevantes se desenvolveram na Argentina e no Uruguai. Segundo ele mesmo informa, auxiliou no planejamento do levante campesino de Hugo Blanco, no Peru, em 1962:

\begin{abstract}
A operação guerrilheira do Vale da Convenção (Cuzco), estrategicamente, se programou em Buenos Aires, eu servi de assessor estratégico. Entre os trotskistas peruanos e argentinos da IV Internacional - POR - existia uma grande afinidade política. Eu nunca fui trotskista, mas fui assessor estratégico para programar a rebelião campesina no Peru (GUILLÉN, 1978) . $^{5}$
\end{abstract}

Ou seja, Guillén esteve vinculado a diversos grupos revolucionários, atuando como teórico e auxiliando seus planejamentos, mesmo que se tratasse de grupos não anarquistas ou auto gestionários. Ele mesmo relacionou seus contatos com grupos brasileiros, sintetizando:

No Brasil havia todas as condições, com muito espaço rural e grandes cidades, para criar o mais vasto movimento guerrilheiro da América Latina. Mas Marighella, que era maoísta, não queria desmentir a Mao e a Fidel

\footnotetext{
${ }^{4}$ Embora saibamos que influenciou também no processo revolucionário chileno, não trataremos desse aspecto. O que buscamos é sua influência em um grupo de brasileiros que clandestinamente se preparava no Chile para voltar ao Brasil.

${ }^{5}$ Esta entrevista foi feita originalmente em 1978 ao Boletín Informativo del Colectivo Internacionalista de Comunicaciones Libertarias y ecológicas de Trabajadores anarco-sindicalistas - Revista Bicicleta, n.9, Barcelona. Utilizo aqui a versão reproduzida em idioma espanhol no site Lapeste.org, em 2018.
} 
quanto ao fato de que a guerrilha no campo é estratégica e a da cidade tática, ou seja, menos importante que aquela. Lamarca também, maoísta e fidelista, logo que ganhou muitos combates em São Paulo, graças a seus audazes golpes de guerrilha urbana (...) foi com todo seu exército a combater em serras [brasileiras] (GUILLÉN, 1978, p. 4).

Não é correto afirmar que Lamarca foi combater no "triângulo entre Rio, São Paulo e Salvador", como ele diz, pois o que se estabeleceu foi um campo de treinamento de guerrilha no Vale da Ribeira, não propriamente de guerrilha. Mas de fato, Lamarca cada vez mais percebia a necessidade de manter as ações urbanas, dadas as dificuldades no campo brasileiro. Os documentos de Lamarca demonstram que ele estava debatendo ideias como as de Guillén. (SILVA, 2021) O contato mais aprofundado com a obra de Guillén se deu por meio da Frente de Libertação Nacional ${ }^{6}$, agrupamento de militantes que clandestinamente no Chile se reorganizavam para luta, como discutiremos adiante.

Como apontamos, a experiência de Guillén vem do processo revolucionário espanhol, no qual o anarquismo tem uma grande relevância, e permite trazer sua experiência com auto gestão. Atua politicamente como estrategista de grupos que buscam a luta armada, os uturuncos na Argentina e os tupamaros no Uruguai. Seus escritos chegariam ao Brasil, como discutiremos na sequência deste artigo.

As discussões sobre as formas de revolução na América Latina estão situadas no contexto da OLAS (I Conferência de la Organización Latinoamericana de Solidaridad), na qual a posição cubana dizia que "o único caminho genuíno para promover a solidariedade era implementar uma estratégia continental de luta armada", ao passo que os soviéticos, que pautavam os partidos comunistas, traziam uma visão "mais moderada que incluía a luta armada como um possível caminho entre outros meios de ativismo político, entre ele a luta eleitoral ou o sindicalismo" (MARCHESI, 2019, p. 27). Já na conferência, que estabelece o foquismo como modelo, há países tidos como menos propícios, colocando que o método não era infalível, pois dependia de condições geográficas, mas sobretudo políticas, não era possível "transplantes automáticos da experiência cubana" (Idem, p. 29). As realidades dos distintos países colocavam a tese em xeque.

\footnotetext{
${ }^{6}$ Enquanto esteve na VPR - Vanguarda Popular Revolucionária - Lamarca buscou fortalecer a FLN, mas os conflitos no caso do sequestro do Embaixador suíço interromperiam esse processo. (SILVA, 2021)
} 
O texto de Guillén, Desafios del Pentágono, de 1969, se dedica a retomar criticamente o tema do imperialismo na América Latina e a criticar o foquismo. Ele defendia enfaticamente a necessidade da guerrilha urbana não apenas no sentido de "levantar fundos financeiros", mas como momento mesmo da guerra revolucionária. Segundo ele, "estrategicamente, o ideal é combinar a guerrilha rural, de montanha e urbana, simultaneamente, para levar o inimigo a uma vasta guerra em superfície de modo a que quando vá ao campo com todas suas forças perda a cidade por um golpe de graça em sua retaguarda" (GUILLÉN, 1969, p. 48). A experiência de Che na Bolívia mostrara as consequências do isolamento com relação à população, fato sobre o qual havia pouca reflexão prática.

No Uruguai, Guillén passa a assessorar os tupamaros. O grupo teve um papel importante como primeira experiência no Conesul que testaria a crítica ao foquismo, para construir uma experiência de luta que se concentrava na ação urbana:

\footnotetext{
Em meados dos setenta uma série de militantes da Argentina, Brasil, Chile e Uruguai se dedicaram a construir novos repertórios de dissenso inspirados na Revolução cubana. Mas ainda que aderissem a ela e a reconhecem publicamente, propunham caminhos diferentes às fórmulas do foquismo rural cubanas (MARCHESI, p. 69).
}

Além de ações urbanas, buscavam sempre dar um caráter político às suas ações, fazendo delas um meio de diálogo com as massas que queriam disputar. O autor explora as relações do grupo uruguaio com outros grupos argentinos, e também relaciona o surgimento do Manual do Guerrilheiro Urbano, de Carlos Marighella, como tributário desse texto. Embora saibamos que a ALN buscasse a ação no campo, sua atuação real se deu juntando forças no meio urbano brasileiro, não "chegou ao campo", objetivo inspirado no foquismo e também na tese da Guerra Popular Prolongada de Mao Tse Tung. Marchesi recupera a influência de vários militantes que propuseram leituras teóricas para os tupamaros. Entre eles destaca-se a ação do ex-combatente anarquista da Guerra Civil Espanhola que viria a influenciar as Forças Argentinas de Libertação FAL, o MIR chileno e posteriormente grupos brasileiros, como discutiremos no último tópico deste artigo. Depois de uma passagem por movimentos de resistência na Argentina, vinculado ao peronismo de esquerda e à experiência de guerrilha dos 
Uturuncos em Tucuman (SALAS, p. 279), Guillén passaria a viver no Uruguai. Segundo ele mesmo, a caracterização peronista do grupo argentino "constituía uma limitação política, pois uma guerra revolucionária deve englobar a todo um povo e não apenas a um partido" (GUILLÉN, 1978, p. 2). Sua experiência seria colocada a prova.

\title{
Abraham Guillén na América Latina
}

Nas organizações uruguaias e argentinas se localizam vários militantes de outras origens de luta e nacionalidades buscando interpretar aquele momento histórico. Trazemos a seguir a análise de um contexto mais amplo em que esses pontos aparecem na obra específica de Guillén. Um estudo sobre ele, realizado nos Estados Unidos, aponta que

\begin{abstract}
A teoria de Guillén sobre a guerrilha urbana demarca uma significativa evolução para as teorias populares de guerra de guerrilha no final dos anos 1960. Sua teoria foi desenvolvida a partir de sua experiência pessoal durante a Guerra Civil Espanhola e catalisa a profunda influência da popular teoria da guerra de guerrilha, incluindo a guerra popular prolongada de Mao Tse Tung e a teoria do foquismo de "Che" Guevara. A teoria de Guillén se torna muito influente na América Latina em meados dos anos 1960 até o início dos 1970. Seus escritos mais notáveis, Estratégia de Guerrilha Urbana também influenciaram guerrilhas nos Estados Unidos, Europa. Japão e no Oriente Médio (GONZALEZ, 2015, p.4).
\end{abstract}

Trata-se, portanto, de uma contribuição muito relevante para o estudo das guerrilhas urbanas estudadas na academia militar estadunidense. Sua crítica parte de problemas reais da disparidade entre as teorias disponíveis e a forma de construção destas nas realidades concretas. Não é, entretanto, conhecida a fundo no meio acadêmico, sobretudo no Brasil. Essa obra citada é um estudo realizado no âmbito militar estadunidense. O próprio autor indica que essa obra é "desacreditada como um conceito que nunca foi bem sucedido na prática". Mas esse não pode ser um critério para avaliarmos o papel que teve naquelas tentativas de inserção social e política dos movimentos nos quais Guillén teve influência. Posteriormente, seus escritos influenciariam diretamente o IRA (Irlanda) e as FARCS (Colômbia), pois inovam na leitura prática das guerras urbanas. 
Segundo a apresentação do livro "Revalorización de la guerrilla urbana", de 1966, republicado em 1975, no México, os editores ressaltam a importância da obra no texto de apresentação:

Transcorreram 10 anos desde o surgimento do primeiro tratado sistemático dos fundamentos da guerrilha urbana: La estrategia de la guerrilla urbana de Abraham Guillén (Montevideo, 1966). A polícia uruguaia, tanto como os tupamaros acreditam que este trabalho proporciona o modelo para a luta de guerrilha urbana não apenas no Uruguai, mas também nos vizinhos Brasil e Argentina (HODGES e GUILLÉN, 1975, P. 3).

O texto avança ao analisar as derrotas e fracassos dos movimentos que se inspiraram nesse modelo. Eles propõem uma síntese:

1. Em uma guerra de libertação a vitória final não é militar, mas política; ganhará o lado que rompa a moral do inimigo, suportando mais tempo em uma guerra de desgaste, na qual o mais leve dano infligido persistentemente ao inimigo, é mais efetivo que fazê-lo correr. 2. Somente uma força de guerrilha com o apoio ativo de uma maioria da população poderá triunfar contra a superioridade militar de um exército regular; isto significa que as pessoas devem ser mobilizadas para que o núcleo guerrilheiro cresça e se transforme em um exército de libertação em grande escala. 3. Estas duas estratégias devem estar tão bem combinadas que as táticas empregadas para romper a moral inimiga contribuam a atrair o apoio da maior parte da população e não provocar seu repúdio (HODGES e GUILLÉN, 1975, p. 4).

Sua obra seguiria influenciando outros grupos, para além da América Latina. Seus dois textos seguintes, sobre violência e sobre Guerrilha são tributários dessa experiência vivida na Argentina e no Uruguai. Ou seja, buscava intervenções práticas nas lutas, o que nos ajuda a compreendermos o alcance de sua dimensão.

Para entender a perspectiva do autor, é preciso lembrar que ele visualiza a repressão também internacionalizada, como um "exército continental repressivo", contra o qual defendia: uma Frente Unida Antimperialista Latino-americana; um exército latino-americano de Unidade e Libertação; uma Central Sindical Unida Latinoamericana; uma frente Unida da Juventude latino-americana, uma federação estudantil latino-americana e um partido dos trabalhadores latino-americanos (GUILLÉN, 1966, p. 43). Apenas uma ação conjunta dos países do sul poderia reagir contra o avanço do Exército ianque por meio do Estado Maior do Pentágono.

Guillén é insistente sobre a necessidade de que o povo latino-americano deve desapegar-se dos nacionalismos "decadente e raquítico" e propagar um nacionalismo 
latino-americano que propague a unidade da América Latina (GUILLÉN, 1966, p. 44.) Certamente seu texto ganharia acolhida por incitar o povo às lutas por libertação, descolonização e à liquidação dos "senhores da guerra". E isso somente seria possível recorrendo a "guerras revolucionárias, combinadas na cidade e no campo", não há lugar para acordos com as burguesias locais. Demarca-se uma resistência às posições dos partidos comunistas. Essa posição ganha acolhida nos contextos de ditaduras sulamericanas, nos quais os partidos comunistas não tinham estratégia de luta armada.

Antes de seguirmos apresentando seu argumento, vale comentar sobre o caráter de sua obra. Vamos utilizar seus livros sobre guerrilha que foram publicados nos anos 1960. Talvez o mais relevante seja o Revalorización de la guerrilla urbana, de 1966. Há diversas versões dessa obra, inclusive se pode localizar uma versão corrigida pelo autor $^{7}$. Utilizaremos aqui o texto reeditado em parceria com Donald Hodges, publicado em 1975. Apenas o texto de introdução é escrito pelos dois autores. O restante da obra é a mesma de Guillén, escrita em 1966.

\section{O foquismo e a revolução nos escritos de Abraham Guillén}

Em que pese o reconhecimento geral da importância das obras de Che Guevara e de Regis Debray para compor o arsenal teórico dos grupos de luta armada na América Latina dos anos 1970, sabemos que suas teses recebiam críticas internas de distintas organizações, ou por não serem adaptáveis às realidades locais em termos geográficos e históricos ou mesmo por trazerem concepções que não encontravam respaldo nas culturas populares locais, sobretudo na relação entre campo e cidade dos distintos países.

Guillén produz uma crítica ao foquismo que recebe acolhida naquele momento da luta. Já situamos que suas ideias circulavam e apontamos o caráter amplo de sua crítica, aferrada aos experimentos concretos que vivenciava. Vamos tentar entender

\footnotetext{
${ }^{7}$ Cotejando o texto com a versão de 1966, não nos pareceu haver perdas significativas para as finalidades deste artigo, por isso sempre que citarmos o texto de 1976, a intenção é trazermos a discussão de 1966. Como apenas a introdução é escrita por Hodges, vamos nos referir ao texto como GUILLÉN, 1976. Nos originais datilografados, de 1966, o texto tem comentários supostamente do próprio autor. Esse texto está disponível na Biblioteca da Universidade da Florida (https://ufdc.ufl.edu/AA00007574/00001)
} 
melhor seus fundamentos, lembrando que tratamos da influência de Guillén nos movimentos de luta armada do início dos anos 1970, ou seja, não posteriormente a esse período.

Cabe recordar que o foquismo parte de uma inspiração na obra de Che Guevara, realizando uma análise crítica de sua obra que propõe uma "guerra de guerrilhas" para estabelecer a tese do foco revolucionário. Nessa tese, o centro da ação revolucionária estaria no campo, atuando em aproximação e conjunto com a população rural e liberando áreas e criando colunas táticas que permitiriam "cercar as cidades". Os problemas da aplicação dessa tese para a realidade brasileira dos anos 1970 são imensos. O próprio Guillén nos ajuda a entender as fases dessa luta:

$1^{\circ}$. O exército inimigo é muito grande e a guerrilha muito pequena, reduzida a um ou mais grupo armado, sem possibilidades e manter-se sobre terreno fixo, para evitar a ofensiva e o cerco do adversário, em razão de sua mobilidade, segurança, velocidade e combatividade; $2^{\circ}$ a guerrilha ganha adeptos e aumenta sua capacidade de combate, podendo defender zonas liberadas, em alta montanha coberta de mata, mas sem aferrar-se muito ao terreno, enquanto que o inimigo passa da ofensiva permanente à política estática de grande cerco sobre uma zona guerrilheira; $3^{\circ}$ os grupos guerrilheiros se convertem em exército de liberação, empregando unidades relativamente grandes e de armamentos semipesados (tomados do inimigo), ainda que este siga mantendo, na retaguarda do adversário, uma enorme guerrilha para tomar ao inimigo entre dois fogos, para levantar a população de uma retaguarda contra ele (GUILLÉN, 1969, p. 71).

Sua obra estuda esses momentos de luta, indicando sua inviabilidade nas realidades concretas em que aconteceram, suas vantagens e desvantagens, sobretudo o fato de que o inimigo (exército) possui uma capacidade de reorganizar diante de perdas imensamente maior que os revolucionários. A geografia e mesmo a geopolítica dos distintos países latino-americanos mostraria essas dificuldades.

Guillén propõe essa leitura no caso da experiência uruguaia. Sua concepção influencia o método do grupo Organização Popular Revolucionária 33 Orientais (OPR33), um braço urbano de ação de guerrilha, ligado à FAU, Federação Anarquista Uruguaia. Ações diretas, mobilização por meio de táticas de autodefesa, assaltos a supermercado realizando distribuição de alimentos eram algumas das ações empreendidas (ALVES, 2014, p. 86). As disputas estavam situadas: "Dentro dessa proposta, disputavam as teses foquista com a maoísta; uma vez conciliadas, foi definido 
um estatuto da nova organização, ainda sem nome, mas sendo identificada, entre seus quadros, como Tupamaros" (ALVES, p. 87), que se chamaria Movimiento de Liberación Nacional-Tupamaros (MLN-T).

$\mathrm{Na}$ sua leitura, as lutas latino-americanas tinham que definitivamente abandonar o foquismo, pois era necessário adentrar as grandes cidades ou a luta não avançaria. Assim, ele relata experiências concretas sobre as quais vai tendo informações para trazer quais seriam os passos a serem tomados. Ao tratar da experiência tupamara, destaca nove pontos de análise: 1) Frente móvel x frente fixa; 2. Mobilidade e segurança; 3. Retaguarda pesada ou leve; 4. Infraestrutura logística; 5. Heróis, mártires e vingadores; 6. Mando delegado; 7. Revolução. Que revolução?; 8. Estratégia, tática e política; 9. OPR-33 e Tupamaros. Atemo-nos a ressaltar os pontos sobre revolução, estratégia e tática. Questões concretas são exploradas, permitindo ver a relação entre a teoria e prática recentes dos movimentos em luta. (GUILLÉN, 1976, p. 35) Não discutimos aqui as especificidades dos Tupamaros, para isso há bibliografia adequada (ALDRIGHI, 2012, e outros textos da autora). Destacamos que esse esquema é relevante para entender os modos organizativos no Brasil, sendo elemento presente em diversos grupos, como a VPR e ALN. Por exemplo, as dificuldades de escolha da opção da clandestinidade total, as ações de massa como justiçamento, entre outros.

Ao tratar a revolução, tema que de imediato se relacionava a Cuba, Guillén abre a discussão criticando a proliferação de "teorias do foco guerrilheiro, predicando o retorno ao campo, para libertar a corrompida cidade, tese principal de Regis Debray. Estas estratégias ruralistas emancipatórias eram uma espécie de retorno à natureza, como a de J.J. Rousseau”. (GUILLÉN, 1976, p. 11). Estabelecida a ironia, o problema era real, a idealização sobre a realidade rural. Nesse sentido, a crítica vai considerar que os militantes urbanos que sonham em realizar a luta rural seriam nada menos que "pequeno-burgueses":

É próprio dos jovens esquerdistas, sem práxis proletária, e sem haver suportado jamais a exploração capitalista, pretender a libertação dos trabalhadores sem a intervenção revolucionárias destes, livrando toda ação revolucionária a uma série de combates militares entre guerrilheiros e o exército repressivo. O 'foquismo' pequeno-burguês magnifica o armamento como símbolo de poder mais que utilizar as armas para por em movimento ao povo, esperando que o exército repressivo venha a castigá-lo e detê-lo em seu 
avanço revolucionário, para, da sua vez, entrar e reprimir ao repressor do povo, ganhando assim a população em cada combate guerrilheiro, único meio de chegar até a revolução (GUILLÉN, 1976, p. 38).

Guillén é taxativo na crítica, reduzindo o foquismo a uma "fábrica de amontoar cadáveres". E por outro lado, a guerrilha se torna demasiado profissional, isolando-se totalmente das massas urbanas, criando um "estado dentro do estado" com suas colunas guerrrilheiras. Por isso ele ressalta e saúda a ação da OPR-33, "guerrilha urbana, diferentemente dos tupamaros, dá cobertura às massas, aos sindicatos e movimentos populares, não caindo no militarismo populista, guerrilheiro e pequeno burguês. (Idem). Parece-nos que essa inflexão seria central para os movimentos que ocorriam no Brasil à altura.

Há ainda outro fator de alta relevância de aproximação entre os métodos de luta no Uruguai, Argentina e Brasil, que é a utilização das táticas de sequestros como atos revolucionários. O debate passa pela relação entre estratégia e tática relacionado às ações de lutas. Sabemos que no Brasil os sequestros foram ações importantes para o salvamento da vida de mais de uma centena de pessoas e representaram também uma inflexão na forma de organização das lutas e da repressão, pois neste país os sequestros se detiveram a tomar membros da diplomacia estrangeira, o que tornava os atos eminentemente internacionais (SILVA, 2020).

Os tupamaros, por sua vez, realizam um sequestro do embaixador brasileiro, Dias Gomide ${ }^{8}$. Como o governo uruguaio não aceitou trocas de indivíduos presos, os tupamaros exigiram recompensa pela vida do embaixador. Como ele não possuía fundos, sua esposa realizou uma campanha de solidariedade internacional. E "cada cruzeiro se convertia em um voto contra os 'tupamaros' e a guerrilha urbana brasileira" (GUILLÉN, 1975, p. 39). Ou seja, foi uma ação que não obteve o uso político que poderia, bem pelo contrário. Reclama o autor que "se devia ter pedido a publicação de um manifesto na imprensa brasileira, cujo conteúdo deveria ser de denúncia contra o “esquadrão da morte”; pedir eleições democráticas e livres” etc. Assim, segue ele:

quando os militares brasileiros do III Exército do RS quisessem se por em movimento para aplastrar a revolução no Uruguai, teriam minada,

\footnotetext{
${ }^{8}$ Sobre o tema, ver: FREDERICO, 2020.
} 
politicamente sua retaguarda. E assim poderia triunfar a revolução no Uruguai: todas as operações de guerrilha não são nacionais, mas regionais, internacionais, segundo as conveniências estratégicas e políticas (Ibidem).

O sequestro, em vez de ter sido um ato político, acabou sendo um ato malvisto, uma arrecadação de dinheiro para os militantes. Assim ele conclui: "se a tática, com seus limitados horizontes trata de condicionar a estratégia e dominar a política, um exército guerrilheiro nunca poderá vencer a um poderoso exército contrarrevolucionário”. Portanto, a estratégia tem que vir antes da tática.

Ao relacionar o ocorrido no Uruguai com a "guerrilha brasileira", o autor diz que: "Lamarca, com sua rica experiência, tanto de guerrilha rural como guerrilha urbana, dizia pouco tempo antes de morrer, entre outras coisas que "a partir da concepção de Marighella, surgiu a concepção de coluna combinada com outras formas de guerrilhas na área estratégica". A partir daí, ele desenvolve seus pontos de análise, propondo dar "luz" aos fatos, para a luta revolucionária, e essa seria a contribuição que seria trazida diretamente ao Brasil.

\section{Os Doze pontos da revolução}

O primeiro ponto "Crítica e autocrítica” é da própria filosofia da luta marxista:

não ter medo de aplicar a dialética a tudo, inclusive a nossos próprios erros, pois essa dialética não se acredita ser uma verdade eterna, mas que tudo está no devenir dialético. Se não sabemos porque perdemos uma batalha não podemos ganhar nenhuma outra no futuro (GUILLÉN, 1975, p. 43).

O segundo ponto trata da análise política do governo do país onde a revolução está em questão, da análise política acerca dele:

não se descobriu, realmente, as leis políticas e estratégicas específicas da revolução brasileira; sem descobrir esse caminho claro, largo, os pretorianos brasileiros poderão ficar muito tempo no poder. Finalmente, quando se vejam debilitados politicamente, como os militares argentinos, podem ir a umas eleições, mas para evitar uma, ou várias revoluções (Ibidem).

Ou seja, aponta um caminho lento dos militares que chegassem ao poder, e controlariam a sua própria sucessão, exatamente o que acabaria ocorrendo no país. O 
ponto 3 indica a necessidade de destruir as forças burguesas e imperialistas em toda a América Latina, o que se daria apenas pela via revolucionária. O caso do Brasil é um exemplo, pois ele já colocara como princípio a necessidade de expansão para a América Latina

mas a revolução para ser um grande movimento de massas, não tem que subordinar-se a velhas ideologias, mas criar sua própria ideologia, seu próprio programa de libertação, que fale mais do que una do que do separe as forças opositoras brasileiras, a fim de que pelos seus choques, disparidades e diferenças ideológicas, não choquem as forças da oposição umas contra as outras, em vez de constituir uma resultante de forças unidas contra a burguesia e o imperialismo (Ibidem).

Não apenas a discussão teórica, mas a formação social de cada caso precisaria ser levada em conta nesse processo. Guillén coloca problemas para a prática de vanguardas revolucionárias. Ele é incisivo em defender que farão a revolução aqueles que estiverem do lado dela. No caso da inexistência de uma vanguarda operária marxista, "a vanguarda revolucionária deve estar integrada pelos revolucionários profissionais, extraídos de não importa qual classe. Marx dizia que quando uma classe está chamada ao poder, e passam para seu lado membros das classes dominantes ou dominadas, então está madura a revolução.” Ele emenda:

Lenin, Marx e Bakunin, Fidel, El "Che", etc, não eram operários, mas revolucionários, ou seja, a "chispa" destinada a acender a pradeira. Esta deve ser a vanguarda revolucionária na América Latina: uma minoria ativa que faça propaganda pelos fatos, pela ação, uma minoria que seja capaz de levantar em armas e em luta política a uma maioria passiva, tudo o demais, é aventureirismo revolucionário, subjetivismo político. (Guillén, 1975, p. 44)

Ou seja, não seria um grupo de "verdadeiros guerrilheiros" que poderiam construir sozinhos o poder popular. A grande questão que aparece no ponto 5 é a medida entre estratégia e tática. É preciso ir além, e o Brasil aparece como exemplo

uma destas organizações deve tentar uma análise, uma síntese do processo revolucionário frustrado até o presente, unificando o pensamento e a ação, o objetivo e o subjetivo, a prática e a teoria, a vanguarda armada e o povo oprimido, mas com mais referência aos aspectos nacionais da luta de libertação [...], a ideologia e políticas estrangeiras, que puderam ser muito úteis em outros países, mas que ali não dão resultado [..], com uma situação distinta objetiva e subjetivamente. Pois não há duas guerras que se façam com a mesma estratégia, nem dois revolucionários com a mesma ideologia (Ibidem). 
Portanto, a práxis revolucionária obrigaria ao exercício teórico a análise, a crítica e a autocrítica obrigam a dar passos além dos textos que estavam simplesmente servindo de guias, como os textos de Che e de Debray. Era preciso realizar sínteses locais. E quem seria o sujeito dessa revolução também deve ser levado em conta em relação à realidade local. A relação com as massas precisa assumir um certo pragmatismo, como consta no ponto 6:

\begin{abstract}
O único caminho justo para a revolução brasileira é o socialismo, onde não se impõe uma vanguarda; mas se esta se forma dentro da classe operária, dirigente autêntica do processo, seria a única capaz de conduzir a revolução até suas últimas consequências. Isso é correto politicamente, mas só dentro dos quadros revolucionários, mas não se deve dizer nada de socialismo nem de coisas similares para fora. A luta cobra nível quando não se submete a uma ideologia prévia; quando se enquadra nos aspectos concretos nacionais. Se Fidel houvesse dito, na Sierra Maestra, que iria ao socialismo, haveria perdido a guerra. O socialismo será consequência da vitória popular; não pode ser de outra forma; mas não se deve pô-lo de bandeira, na luta contra o imperialismo e as burguesias nacionais; se deve falar de coisas concretas: mover a população por meio das ações da vanguarda revolucionária operária ou estudantil -, não importa, por quem seja; mas sem encher-se a boca de socialismo, senão, de melhor forma, de nacionalismo (Ibidem).
\end{abstract}

Não existe a revolução sem as massas, mas o seu aprendizado pode ser lento. E cabe à vanguarda perceber o sentido das palavras. Disputar o sentido seria mais importante que impor um vocabulário. Entretanto, tudo isso precisa estar subordinado a uma estratégia, ponto no qual ele insiste:

7. É necessário buscar uma nova orientação estratégica, depois de uma verdadeira autocrítica, encontrando formas e métodos mais adequados, para seu enquadramento prático, adquirindo novos dados teóricos que enriqueçam a teoria revolucionária operacional, correta, prática, eficiente, não sempre no limbo da improvisação, confundindo tática com estratégia (Ibidem).

Ele tira um grande ensinamento da análise. Perceba-se que ele vê no Brasil a existência dos dois campos, "guerrilhas rurais e urbanas", o mesmo problema que coloca para a análise uruguaia. E percebe que a burguesia vai ganhando batalha após batalha, especialmente na forma de atuar junto às massas e suas manifestações vulgarmente tidas como espontaneístas: 
Nas ações revolucionárias, a gente não deve se separar das massas; temos que segui-las em seus interesses, para despertar o entusiasmo revolucionário nelas. Por tanto, as ações devem atuar contra a burguesia (patronal) e contra o Exército (burguesia armada) ou contra o imperialismo (para fazer respeitar aos operários) ante seus exploradores de dentro e de fora. Toda estratégia deve concretar-se nisso: dar abertura a todos os movimentos de massas: estudantes, operários em greve, campesinos famintos e posseiros, e baixo clero (que se opõe à ditadura e está com o povo). Neste caso, para lançar à Igreja fora de seus tímidos bispos, temos que tomar de sequestro a personagens de grande valor e significação no regime pretoriano, trocando-os por padres terceiro-mundistas presos. Isso dá à luta um caráter amplo, sem necessidade de encher-se a boca com socialismo nem marxismo-leninismo. Isso temos que aplicar como doutrina, não dizê-lo permanentemente (Ibidem).

Percebe-se que é uma leitura muito longe do compromisso partidário comunista. Em outros momentos, Guillén permite que se vislumbre como essa aproximação com o povo se daria, ficando clara a defesa de práticas auto gestionárias ${ }^{9}$. Em um quadro de ditadura, a contradição fundamental a ser trabalhada é entre imperialismo e povo. Pouco se avançaria pregando contra a contradição fundamental capital x trabalho. Ela precisaria ser politicamente colocada "este ponto constitui a chave de toda a política e a estratégia, para o triunfo em uma guerra de libertação nacional". Ou seja, libertar o povo do imperialismo, o que seria uma tarefa além das fronteiras nacionais, ou estaria fadada ao fracasso. Nesse sentido, a questão nacional reaparece no fechamento do documento:

11. A prioridade de nosso trabalho político, inclusive por ações armadas, quanto à divulgação de nossos ideais, deve ser a preocupação principal. Nos meios operários, as ideias socialistas devem ser divulgadas, mas no aspecto nacional, há que nacionalizar a luta. Marx disse que, em uma revolução sempre triunfa, 'o' ou 'os' revolucionários que sabem colocar melhor a questão nacional, para colocar o povo em armas. 12. Todas as formas de luta, armadas ou não, são válidas desde que no espaço e no tempo e na oportunidade tenham "ocasião histórica", ou a criem, pouco a pouco, para que a ação do particular (a guerrilha), crie a rebelião geral (o povo em armas).

O documento, na forma como conta na documentação do Centro de Inteligência, diz que se os "amigos brasileiros" tivessem aplicado essas conclusões não teriam sido mortos Marighella, Lamarca ou tantos outros grandes revolucionários. Para

\footnotetext{
${ }^{9}$ Ele desenvolve em outra obra especificamente o aprendizado com as experiências auto gestionárias da República Espanhola (Guillén, Teoria de la violencia, Buenos Aires, 1965). Esse aspecto é ressaltado em sua biografia (MIRAMAR, 2020).
} 
fazer a revolução é necessário ter "uma práxis coerente: unidade do pensamento e da ação, no sentido da dialética marxista pois o próprio Marx disse: minha teoria não é mais do que para ser aplicada a uma situação concreta, não para ser repetida" ${ }^{10}$ Esse é o sentido do que ele busca, a partir das experiências uruguaia e brasileira, embora no caso da segunda, sem conhecê-la pessoalmente, até o ponto que se sabe.

Uma das táticas discutidas volta a ser o uso de sequestros de personalidades, e Guillén é taxativo ao defender que deveriam sempre ter um objetivo político geral, realizar denúncias que visassem com tal ato ganhar a população:

\begin{abstract}
Não há que fazer as trocas de embaixadores ou cônsules estrangeiros contra guerrilheiros detidos, mas levantar a toda população contra um governo odiado. Somente assim a ação vai ganhando a população, pois assim a guerrilha se faz grande e o exército que a reprime se apequena, pois se um decresce, como sucede a um polo de contradição vital, dialética, concreta (GUILLÉN, 1975, p. 50).
\end{abstract}

Os casos de sequestros no Brasil, que salvaram a vida de militantes presos, nunca passaram de ações táticas, foram usados à extensão na Argentina. Obtiveram sucesso relativo no Uruguai, mas Guillén explicita que não passariam disso, não avançam do ponto de vista estratégico, tanto é que seriam abandonados, mesmo como tática. No caso uruguaio, o próprio texto do autor aponta para o caminho a uma "Frente Ampla mas revolucionária", e anota os sujeitos dessa frente: classe operária; camponeses; classe média economicamente débil; parte da burguesia pequena e média; parte da Igreja não comprometida com ditaduras; estudantes. $\mathrm{O}$ inimigo estava estruturado entre oligarquia terratenente, tecnocratas e altos burocratas, plutocracia industrial, mercantil e financeira e militaristas reacionários (GUILLÉN, 1975, p. 5152). ${ }^{11}$

Diante disso, apenas mimetizar o militarismo inspirado no exemplo cubano de 1959 era insuficiente:

"o retrato de "Che" Guevara, colocado em conferências de imprensa clandestinas acordadas entre jornalistas e grupos guerrilheiros pode ter muito significado simbólico para eles, mas os define como castristas ante a opinião pública; e este grave erro político já é suficiente para isolá-los de uma frente

\footnotetext{
${ }^{10}$ Tesis sobre la guerrilla en el Brasil. Abraham Guillén, 1972.

${ }^{11}$ Para seguir o caminho que seria trilhado pelos tupamaros, ver ALDRIGHI, 2012.
} 
ampla democrática contra uma ditadura militar a qual tente derrotar" (GUILLÉN, 1975, P. 52).

Talvez essa seja a síntese da sua proposta, a necessidade de romper com o militarismo da luta armada. A percepção de que os símbolos da luta fazem sentido para os que lutam, mas não para os que necessitam dela e são submetidos a distintas guerras de opinião pública e midiática. Esse amplo documento de discussão, que se propõe a defender a guerrilha urbana no contexto latino-americano seria reduzido em seus "doze pontos" por militantes brasileiros que se reorganizavam no Chile. Embora não encontremos referência a tal contexto na literatura, a repressão brasileira ajudou a criar mecanismos para sua difusão com o fim de atrair brasileiros que estavam no exterior para serem vítimas no país, como ocorreu em vários casos no país (SILVA, 2021), como apontaremos a seguir.

\section{Guillén acompanhado pelo serviço de inteligência brasileiro}

No Chile, durante o governo de Salvador Allende, vários revolucionários latino-americanos buscaram formas de retomar suas organizações, repensar a revolução. Foi o caso da FPI - Frente Política Ideológica, que reunia brasileiros que queriam voltar ao país para seguir a revolução, mesmo que as condições fossem as piores possíveis. Há indícios de haver dinheiro vindo por Cuba e contatos com a Argélia. A FPI esteve bastante infiltrada pela repressão, que se utilizou dessa discussão a fim de estimular militantes a voltarem ao Brasil, a fim de exterminá-los. Para isso, o esquema envolvia uma presença de repressores no Chile e espiões no Uruguai, denotando uma colaboração repressiva anterior ao esquema Condor ${ }^{12}$ Lembremos que o próprio Guillén ressaltava a relevância de seus textos, indicando que o Mini manual de guerrilha, de Marighella, fora diretamente inspirado em sua obra. Ele se refere diretamente ao "Mayor Piriz", referência repetida em sua biografia (MIRAMAR, 2020, p. 210), que era o centro da organização de brasileiros no Chile, buscando a volta ao Brasil para seguir a luta armada.

\footnotetext{
${ }^{12}$ Sobre as formas de atuação do CIEX, ver: DIAS, 2019.
} 
Um documento do CENIMAR (Centro de Informações da Marinha Brasileira) indica que essa Frente começou a ser criada em novembro de 1971 por Joaquim Pires Cerveira (Major Piriz) e Plinio Petersen Pereira, no Chile. Ressalte-se, entretanto, que as ações seriam desenvolvidas no Brasil, e por isso eram acompanhados pela repressão brasileira atuante naquele país. Eles teriam feito contatos com tupamaros "visando obter apoio político do PC italiano para a parte financeira" ${ }^{" 13}$. Teriam então começado arregimentação de pessoas que atuavam em várias organizações no Brasil, "principalmente do pessoal que estava no exterior". Elaboraram o documento Nova Política da Revolução Brasileira, assinado por várias organizações. Esse documento passou a ser sintetizado no chamado "Doze pontos fundamentais" e "se constituía na visão política-revolucionária” da FPI, “compromissando-se a dar uma nova orientação ao desenvolvimento da subversão no Brasil”". A partir daí, o documento sempre é tributado a Guillén, pois são um recorte do seu texto (sem que isso seja informado na sua circulação). Diz o informe que o documento foi bastante discutido e enviado para as organizações radicais no Brasil, tendo sido rejeitado pela ALN, mas apoiado por outras organizações de linha cubana, segundo o informe.

Os mesmos problemas que aparecem na análise dos tupamaros voltam no caso do Brasil. Um dos elementos que estaria na sua síntese crítica do movimento até então é o fato de que "não se ligaram às massas, não conseguindo captar quase nada das ações militares, já efetuadas que lhe poderiam dar maior proveito com os sequestros". Advertem que "não se pode pensar hoje, no Brasil, em travar uma luta contra a ditadura sem fazer um projeto global de guerra revolucionária em nível nacional". O documento faz uma análise do momento de refluxo que se vivia:

Sob o ponto de vista ideológico, as organizações subversivas no Brasil, que passam, neste momento por um processo de depuração, fazem as mais azedas críticas, pois, afirmam nas suas discussões, que se formou uma vanguarda composta na maioria com elementos que não passavam de militantes de base ou simpatizantes. ${ }^{14}$

\footnotetext{
${ }^{13}$ Frente Política Ideológica. CENIMAR, Secreto, 20/10/1972

${ }^{14}$ Idem, p. 2 
A realidade apontada no documento está em consonância com o que sabemos que aconteceu com grupos de luta armada no Brasil. Na medida em que quadros de direção vão caindo, os que sobram, sem preparo, acabam dando tudo de si para manter a organização, mas não necessariamente conseguem. Esse documento, que deve ter contado com a participação desses militantes que restavam no Chile, faz projeções irreais sobre o que ocorria no Brasil, dando a falsa ideia de avanço da luta. Indicava também

Aproveitar todas as forças que se propõem a fazer qualquer tarefa que sirva à subversão. Um padre, segundo dizem, não pega uma metralhadora, podendo, porém, exercer função mais importante que é a comunicação de massa. ${ }^{15}$

O método segue exatamente o que era proposto por Guillén. Relata-se ter havido uma reunião em São Paulo que teria deliberado pela realização de um sequestro para libertação de padres, "sem necessidade de falar em socialismo ou marxismoleninismo para as massas". Seria uma ação de aproximação com a classe, mais uma vez, vanguardista. O documento encerra dizendo que em pouco tempo a Frente estaria atuando no Brasil. "Sua meta inicial: ações de sabotagem, ações econômicas de grande vulto (tipo cofre do Ademar) e ações de justiçamento"16. Ou seja, essa nova organização manteria acesa a chama da esperança da volta ao Brasil, de seguir a ação revolucionária no país. Veremos a seguir que essa proposta é usada pela repressão para ser convincente, utilizando-se das elaborações de Guillén, à sua revelia.

\section{Lições da Guerrilha latino-americana}

O texto de Guillén chega ao Brasil de uma forma recortada por meio de uma tentativa de órgãos da repressão atraírem de volta ao país militantes que estavam no Chile, na Argentina e no Uruguai. O relatório da "missão no Brasil" realizada por um espião uruguaio trouxe fortes indícios sobre como a espionagem estava funcionando. Contava com o fato de que o militante brasileiro Gilberto Faria Lima era "companheiro

\footnotetext{
${ }^{15}$ Idem, p. 3.

${ }^{16}$ Idem, p. 4.
} 
de toda confiança" ${ }^{17}$ de Cerveira, e aquele fazia contatos com Johnson18, que era um agente espião. Buscavam, a partir do texto, criar terreno para a volta dos militantes que estavam fora do país, sendo assim presas fáceis da repressão.

Em termos teóricos, há a aproximação com o pensamento do teórico espanhol, a própria repressão o tratava como referência para os tupamaros, sendo considerado seu "mentor intelectual". Guillén era já conhecido no CIEX (Centro de Inteligência Exterior):

\begin{abstract}
Baseado no "Documento dos doze pontos, distribuído internamente por subversivos brasileiros no Chile, e encaminhado ao Uruguai, o líder subversivo uruguaio, ABRAHAM GUILLÉN elaborou um estudo dos problemas ligados à revolução na América, sob o título Tesis sobre la revolución en America. O citado documento trata de política, estratégia e tática, passando, em seguida, à experiência guerrilheira no Brasil, criticando todo o processo revolucionário brasileiro e apresentando diretivas, dizendo que la revolución para ser um gran movimento de masas no tiene que subordinarse a viejas ideologias, sino crear su propia ideologia en su próprio programa de liberación. ${ }^{19}$
\end{abstract}

O documento do serviço secreto pedia que não fosse dada difusão, "por razões de proteção à fonte". O relatório de Johnson mostra como a obra de Guillén foi usada para convencer militantes sobre supostos avanços da luta no Brasil. Indicava como objetivos da "missão no Brasil": "discussão política, ordem para ações, contatos paralelos com a ALN, extração de um documento interno, explanação do trabalho que está sendo feito no Chile. Estabelecer contato entre São Paulo e Rio". Diz claramente: "procurar influir com o nome de Abraham Guillén, entregando crítica deste aos Doze Pontos e livro Desafio ao Pentágono". E ainda, "propor tanto no Rio como em São Paulo a extração de um documento conjunto e enviá-lo para a embaixada da Argélia no Rio para atingir Argel, Chile, Cuba etc”. Além disso, as instruções de segurança

17 Carta manuscrita de Cerveira. Não ignoro que haja suspeita sobre Faria Lima no caso de sua participação em 1971 no MRT, ainda no Brasil. Mas essa documentação não prova que ele estivesse mudado de lado e estivesse colaborando voluntariamente com a repressão.

${ }^{18}$ Sobre ele, ver FERNANDES, 2018.

${ }^{19}$ CIEX 264/72, C-3. Documento de organizações subversivas. ABRAHAM GUILLÉN, 17/5/1972. 
indicam que o agente não deve "dizer que vive no Uruguai" para "não identificar a área" ${ }^{20}$.

Muitas pessoas procuraram o agente Johnson em sua estadia no Brasil, cacifado por estar "em nome de Guillén”, pois sabiam que ele era "credenciado pelos dirigentes do Chile" ${ }^{21}$, o que demonstra a tentativa desesperada de contato com os militantes que lá estavam. Ele relata ainda que discutiu por muito tempo o documento dos Doze Pontos com militantes que, por fim, acabavam aceitando as teses. A sua tarefa se completa com a aprovação de um documento:

\begin{abstract}
Reunidos o MRT-FLN e outros companheiros de diversas organizações vem de constituir um agrupamento revolucionário fundamentando sua decisão num documento intitulado "Os doze pontos", que constitui a sua visão política-revolucionária. Afirmamos que a revolução brasileira se encontra estagnada sob três aspectos: ideológico, político e militar; afirmativa de que a violência revolucionária é a mais correta na atual conjuntura nacional; afirmamos que a formação de uma verdadeira vanguarda revolucionária é a única capaz de dirigir a revolução; afirmativa de que a formação de quadros no político, no ideológico e no militar será capaz de modificar à nosso favor o quadro da luta reinante no Brasil, pois a "Ditadura não oferece outra alternativa do que a violência armada. Proclamamos que principal contradição no Brasil é entre o Capital e o Trabalho, mas prestemente, a mais importante é a que se trava entre a Ditadura, o imperialismo e o povo brasileiro. Finalmente, proclamamos que, no seio da classe operária, força motriz da revolução, sairão as vertentes que conduzirá todo o povo brasileiro para a luta de libertação nacional. Brasil, agosto 1972.
\end{abstract}

Outro documento do CIEX também indicava que "organizações subversivas, no Chile estariam providenciando contatos no Brasil (VPR, FLN e outra não identificada)",22, com a finalidade de levar uma mensagem" que teria como fim "discutir o documento elaborado no Chile conhecido como Documento de Doze Pontos". Ele indicaria que "as organizações subversivas estariam sem reorganização, planejando novas táticas e elaborando nova estratégia revolucionária”, que passaria por novo ciclo de sequestros. O tema segue sendo trazido ao CIEX, exatamente no quadro descrito por Johnson, e sintetiza o documento, o órgão dá difusão ao mesmo documento. ${ }^{23}$

\footnotetext{
${ }^{20}$ Missão no Brasil, 14/7/1972. O conjunto consta das páginas datilografas pelo agente que indica "partida de Montevidéu entre os dias 28 e 30 de julho", cartas manuscritas de Cerveira e Calazans e texto de Guillén datilografado e com correções manuscritas à margem. Arquivo Nacional. BR ANBSB, 25.1.

${ }^{21}$ Idem, p. 12.

${ }^{22}$ CIEX, 029, 10/1/1972. Movimentação de organizações revolucionárias brasileiras.

${ }^{23}$ CIEX, 286, 58/6/1972. Chile. Documento da FBI. Embaixada da Argélia no Brasil
} 
Não há dúvidas de que a repressão usou esse documento como chamariz, e tentava seguir o seu rastro, iria usá-lo como isca para aqueles peões que se moviam em torno de seu tabuleiro. A necessidade de ação, isolamento, dificuldade de contato com o Chile facilitou a aceitação desse emissário, o espião, que ajudou a rearticulação dos grupos. Isso fez parte da ação da repressão que preparava novas armadilhas, pois os principais envolvidos seriam todos mortos. Talvez o golpe de Estado de Pinochet tenha sido decisivo para frear esse esquema, e a caçada tomaria outra forma. Cerveira foi sequestrado em Buenos Aires no dia 5/12/1973, juntamente com João Batista Rita. Trazidos para o Brasil foram barbaramente torturados em São Paulo e no Rio de Janeiro para que obter informações sobre o contexto que estamos narrando. Mortos, ainda constam como desaparecidos políticos ${ }^{24}$.

\section{Considerações Finais}

O caso analisado aponta para a possibilidade de aprofundar a leitura da contribuição de Abraham Guillén. Também aponta para as relações entre a experiência dos tupamaros e os demais grupos de luta no Brasil. Ressalta-se o quanto a repressão estava ligada aos acontecimentos, chegando a forjar situações para aproximar militantes e assim facilitar seu aniquilamento. Os documentos mostram que o Centro de Inteligência brasileiro acompanhava as movimentações no Chile e no Uruguai. Usaram a aproximação programática dos militantes, aproveitando-se dessa tentativa de realizar uma leitura teórica que aproximasse os países da definição da revolução latinoamericana dada pela OLAS.

Em nenhum caso o foquismo foi apenas uma aplicação automática. Embora se construísse como uma forma de tabu as leituras de Che Guevara e Regis Debray, sobretudo pelo compromisso político assumido com relação a Cuba, os movimentos de resistência latino-americanos buscaram construir suas experiências a partir de leituras próprias. Muitos desses vínculos ainda estão para ser descobertos.

\footnotetext{
${ }^{24} \mathrm{http}: / /$ memoriasdaditadura.org.br/memorial/joaquim-pires-cerveira/ 
Não descartamos que Carlos Lamarca e Carlos Marighella tenham tido acesso direto aos livros de Guillén. Ressaltamos aqui o uso que foi feito de uma parte pequena de sua obra, que teve ampla circulação entre os limitados militantes que restavam no Brasil em finais de 1972. Os militantes que se reorganizavam no Chile tiveram espaço para estudar e buscar alternativas, mas as informações que chegavam a eles sobre o que de fato ocorria no Brasil eram truncadas e infiltradas. O compromisso de voltar ao país para seguir a luta falaria mais alto.

Acabaram fugindo uma vez mais para a Argentina depois do golpe de Pinochet. E de lá, muitos ainda foram vítimas de desaparecimento, como o caso dos militantes da VPR atraídos a partir de Buenos Aires já em 1974 (PALMAR, 2019). Um chamariz parecido com o que fora realizado também com os militantes mortos na chacina do Recife (CAMPOS, 2017). No meio de tanta desmemória produzida pela repressão, os textos de Guillén nos abrem um novo caminho a explorar sobre a luta armada latinoamericana.

\section{Referências Bibliográficas}

ALDRIGHI, Clara. El Movimiento de Liberación Nacional Tupamaros (1965-1975). Estructura interna, fases de desarrollo y política de alianzas. In: POZZI, Pablo y PÉREZ, Claudio (Ed). Historia oral e historia política. Izquierda y lucha armada em América Latina, 1960-1990. Santiago: LOM, 2012.

ALVES, Daniel Augusto de Almeida. Arriba los que luchan! Sindicalismo revolucionário e luta armada. A trajetória da Federação Anarquista Uruguaia. 19631973. Dissertação de Mestrado, PPGH/UFRGS. 2014.

CAMPOS, Luiz Felipe. O massacre da Granja São Bento. 2. ed. Recife: Cepe, 2017.

DIAS, Cristiane Medianeira Ávila. Minha terra tem horrores: o exílio dos brasileiros no Chile (1970-1973). Tese de Doutorado em História. UFRGS. 2019.

FERNANDES, Ananda Simões. Burocratas da dor: as conexões repressivas entre os órgãos de informação das ditaduras brasileiras e uruguaia (1973-1985). Tese de Doutorado. UFGRS. 2018. 
FREDERICO, Fabio. Política externa e guerrilha no Cone Sul: o "plano satã" e o sequestro do diplomata brasileiro Aloysio Mares Dias Gomide, Brasília: fundação Alexandre Gusmão, 2020.

GONZALEZ, Manuel. Abraham Guillén: A Relevant Theory for Contemporary Guerrilla Warfare. Monografia da MAJ. United States Army. 2015.

GUILLÉN, Abraham. Abraham Guillén: el primer teórico de la Guerrilla Urbana (Entrevista). Revista Bicicleta. Boletín Informativo del Colectivo Internacionalista de Comunicaciones Libertarias y ecológicas de Trabajadores anarco-sindicalistas, n.9, Barcelona.

GUILLÉN, Abraham. Desafio al Pentágono. Montevideo: Andes, 1969.

GUILLÉN, Abraham. Estrategia de la Guerrilla Urbana. Montevideo: Manuales del Pueblo, 1966.

GUILLÉN, Abraham. Lecciones de la Guerrilla Latinoamericana. In: HODGES, D \& GUILLÉN, A. Revalorización de la Guerrilla Urbana. Montevideo: Editorial Virtual Liberación, 1976.

GUILLÉN, Abraham. Teoría de la violencia. Buenos Aires: Escorpio, 1965.

GUILLÉN, Abraham. Tesis sobre la guerrilla en el Brasil. Abraham Guillén, 1972 (manuscrito, CIEX).

MARCHESI, Aldo. Hacer la revolución. Guerrillas latino-americanas, de los años sesenta a la caída del Muro. Buenos Aires: Siglo XXI, 2019.

MIRAMAR, José Luis Carretero ABRAHAM GUILLÉN: Guerrilla y autogestión. MADRID. Confederación Sindical Solidaridad Obrera, 2020.

PALMAR, Aluízio. Onde foi que vocês enterraram nossos mortos? São Paulo: Alameda, 2019.

SALAS, Ernesto José. “Uturuncos'. Los Orígenes de la guerrilla peronista (1959-19600. In: POZZI, Pablo y PÉREZ, Claudio (Ed). Historia oral e historia política. Izquierda y lucha armada em América Latina, 1960-1990. Santiago: LOM, 2012.

SILVA, Carla. A Revolução da VPR, a Vanguarda Popular Revolucionária. Uberlândia: Navegando, 2021.

SILVA, C. L. Sequestros e terrorismo de Estado no Brasil: casos de resistência revolucionária. IZQUIERDAS (SANTIAGO). v.49, p. 1646 - 1669, 2020. 